\title{
A velhice na obra de Ronaldo Fraga
}

\section{Débora Pires Teixeira}

Doutora, Universidade Federal Rural do Rio de Janeiro / deborapite@gmail.com Orcid: 0000-0002-3143-8676 / lattes 


\title{
A velhice na obra de Ronaldo Fraga
}

\begin{abstract}
RESUMO
O objetivo desse artigo é analisar a representação da velhice na obra do estilista brasileiro Ronaldo Fraga. Metodologicamente, constitui-se de uma reflexão teórica sobre velhice e moda, a partir de três desfiles do estilista no São Paulo Fashion Week $(2009,2017,2018)$, nos quais o velho apareceu como modelo. Percebe-se que Fraga propõe a ruptura das representações negativas da velhice, tal como a feiura, 0 isolamento social, a inatividade etc. $E$, do contrário, os desfiles mostram possíveis subversões dessas representações, na qual os velhos são convidados por Fraga a assumirem seus símbolos do envelhecimento e a encontrarem beleza neles.
\end{abstract}

Palavras-chave: Ronaldo Fraga. Velhice. Publicidade de Moda. 


\title{
Old age in the work of Ronaldo Fraga
}

\begin{abstract}
The purpose of the article is to analyze the representation of old age in the work of Brazilian designer Ronaldo Fraga. Methodologically, it consists of a theoretical reflection on old age and fashion from three stylist shows at São Paulo Fashion Week (2009, 2017, 2018), in which the old man appeared as a model. It is clear that Fraga proposes to break the negative representations of old age, such as ugliness, social isolation, inactivity, etc. On the contrary, the parades showed possible subversions of these representations, in which the old people are invited by Fraga to assume his symbols of aging and to find beauty in them.
\end{abstract}

Keywords: Ronaldo Fraga. Old age. Fashion Advertising. 


\title{
La vejez en el trabajo de Ronaldo Fraga
}

\begin{abstract}
RESUMEN
El propósito del artículo es analizar la representación de la vejez en el trabajo del diseñador brasileño Ronaldo Fraga. Metodológicamente, consiste en una reflexión teórica sobre la vejez y la moda de tres desfiles de estilistas en la São Paulo Fashion Week (2009, 2017, 2018), en la que el anciano apareció como modelo. Está claro que Fraga propone romper las representaciones negativas de la vejez, como la fealdad, el aislamiento social, la inactividad, etc. Por el contrario, los desfiles mostraron posibles subversiones de estas representaciones, en las cuales los viejos son invitados por Fraga a asumir sus símbolos del envejecimiento $y$ encontrar belleza en ellos.
\end{abstract}

Palabras clave: Ronaldo Fraga. Vejez Publicidad de moda. 


\section{INTRODUÇÃO}

"Eu detesto roupa muda. Então a minha roupa, por mais difícil que seja, ela tem que ter fala" (FRAGA, 2009).

Distante de atender ao modelo de beleza jovem imposto pelo segmento, os velhos foram excluídos da publicidade de moda até o início do século XXI, período no qual começa a se perceber a presença dessa faixa etária nos espaços divulgativos das marcas. Aliando-se as tendências mundiais de representatividade, os profissionais de marketing têm investido na incorporação dos modelos mais velhos, também denominados de modelos maduros, na publicidade de moda (LOPEZ Y ROYO, 2014; MACKINNEY-VALENTIN, 2014; MENDONÇA; FERREIRA， 2014; 2014; POLLINI, 2014). Ademais, pesquisas mostram que os consumidores com 60 anos ou mais tendem a concordar com a adoção de modelos representativos na publicidade de roupas para idosos (EUNKYOUNG; EUN-YOUNG, 2009), bem como apresentaram maior predisposição em comprarem roupas divulgadas por eles (KOZAR; LYNN DAMHORST, 2008).

Nos mercados internacional e nacional verifica-se a atuação de modelos longevos nas principais semanas de moda e na publicidade. No São Paulo Fashion Week (SPFW), a presença de modelos em idade avançada foi observada a partir de 2004, na coleção da Zapping. O então diretor de marketing da marca, Dipa di Pietro, "justificou a campanha dizendo que a moda tem a obrigação de propor reflexões. É uma postura nossa aceitar as diferenças e quebrar padrões conservadores de comportamento" (REVISTA CLAUDIA, 2004, p. 131). 
Nos anos de 2009, 2017 e 2018, Ronaldo Fraga apresentou modelos velhos em seus desfiles do São Paulo Fashion Week ${ }^{1}$.

O interesse de Fraga pela temática da velhice em interface com o universo da moda se deu em 2005, a partir de um evento ocorrido em uma das lojas de roupas do estilista, em Belo Horizonte, na qual ele presenciou o constrangimento de Magnnolia, uma cliente de 80 anos, ao perguntar sobre a existência de roupas para ela:

A partir daquele dia até a sua morte, no ano passado, Magnolia se tornou uma das minhas clientes mais fiéis, vestindo e desfilando pelo mundo as várias histórias das minhas coleções. A partir dali passei a pensar no manto da invisibilidade que era imposto às pessoas no Brasil depois de cruzarem a linha dos 60 anos. O pink e o verde-limão da juventude davam lugar ao salmão apastelado e ao verde-águavovó, da mesma forma que os velhos se tornavam invisíveis aos olhos da sociedade (FRAGA, 2017).

Partindo do posicionamento de Ronaldo Fraga em visibilizar um público que, tradicionalmente, é negligenciado pelo mercado de moda, o objetivo do presente artigo é produzir uma análise a respeito da representação da velhice nos desfiles do estilista.

Metodologicamente, o artigo é constituído por uma reflexão teórica a respeito da representação da velhice na publicidade de $\operatorname{moda}^{2}$, tendo como referência imagens extraídas de três desfiles de Ronaldo Fraga no São Paulo Fashion Week, nos quais o idoso apareceu como modelo: Tudo é risco de giz, Inverno 2009/SPFW; As praias desertas continuam esperando por nós dois, SPFW/2017 e A Colina da Primavera, 2018/SPFW.

Os desfiles foram selecionados pela representatividade da marca no cenário nacional, bem como a repercussão 
midiática das coleções. Ronaldo Fraga, estilista e empresário da marca homônima, representa uma das principais referências criativas ${ }^{3}$ do mercado de moda brasileiro. Fraga defende a noção de moda como manifestação cultural e utiliza suas coleções para suscitar a reflexão social crítica a respeito de temas relevantes em cada época e contexto, como um ato político.

A seleção das imagens atendeu ao critério de relevância para as discussões propostas nesse estudo e foram extraídas de fontes fornecidas pelo estilista, como sites e redes icnográficas: Flickr e Instagram.

$\mathrm{Na}$ análise das fotografias foram consideradas as mensagens emitidas pela comunicação não verbal dos corpos (pele, cabelos, forma, posicionamento corporal etc.), das roupas e dos acessórios utilizados pelos modelos (formas, comprimentos, volumes, referências de moda e materiais). Também foram considerados os textos produzidos pelo próprio estilista (releases e entrevistas), pela mídia especializada na cobertura do evento e pesquisas acadêmicas publicadas por estudiosos que se dedicaram ao estudo das coleções de Fraga, como Pereira (2012).

O referencial teórico mobilizado para análise partiu da perspectiva cultural, com enfoque nos estudos corporais: a Antropologia do Corpo, considerando autores como Le Breton (2010) e Goldenberg (2002, 2007, 2010). Adicionalmente, as obras de Beauvoir (1976) Debert (2003, 2004, 2012), Peixoto (2006) e Sibilia (2012), cujas temáticas tratam da velhice, ofereceram ferramentas analíticas capazes de contribuir para a compreensão dos desfiles selecionados.

\section{COLEÇÃO TUDO É RISCO DE GIZ, INVERNO 2009/SPFW}


No ano de 2009, a coleção de Ronaldo Fraga foi inspirada no espetáculo teatral Giz, do grupo Giramundo, sob direção de Álvaro Apocalypse. Tendo como referências o desamparo e o abando, o estilista julgou que modelos tradicionais não eram adequados para representar tais temáticas (FRAGA, 2009).

Tudo é risco de giz é uma coleção cujas roupas se destinam ao público adulto e infantil. Moletons, túnicas alongadas, blazers, peças em tamanho over, estampas tridimensionais e listras estiveram presentes como protagonistas. A cartela de cores, trazia, principalmente, o branco, preto e tons de cinza, bege, off white. Como afirma o estilista: (...) eu começo com um branco, que vai sujando, vai ganhando traço, que vai sendo rabiscado e a história vai sendo escrita (FRAGA, 2009).

O desfile contou com a participação de idosos (65 a 92 anos) e crianças (5 a 8 anos) como modelos e cenografia foi composta por bonecos-marionete do espetáculo Giz, que se moviam durante o desfile, como mostra a Figura 1:

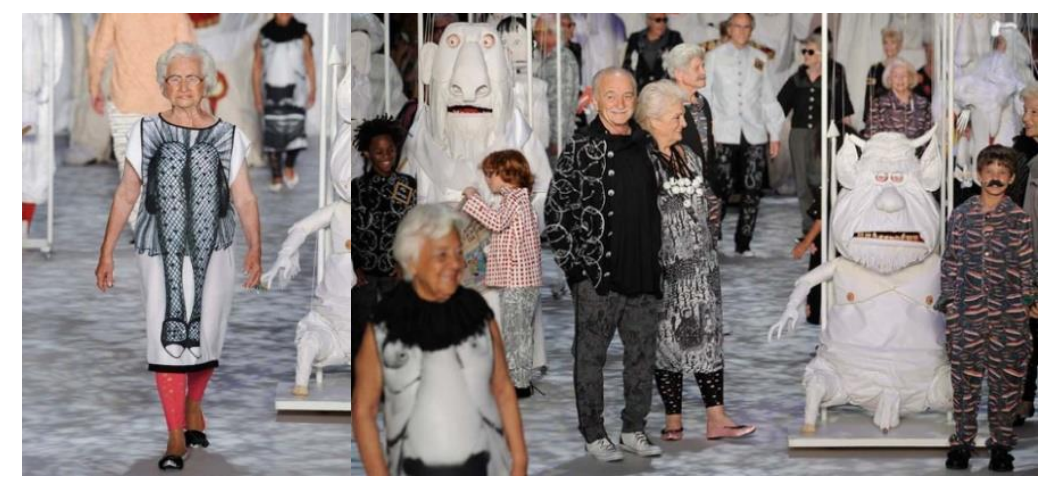

Figura 1: Tudo é risco de giz Fonte: FLICKR RONALDO FRAGA, $2009^{4}$.

Segundo o estilista, a passarela representaria a movimentação comum de pessoas, a vida acontecendo. $\mathrm{Na}$ release da coleção consta: 
Atemporal, ele fala do novo e do velho como início e fim do traço. Universal, ele cria personagens-bonecos, espelhos do homem comum, pendurados como o velho vestido esquecido no cabide. (...) O tempo escorre e até as sereias envelhecem. (...) Nesta coleção, as roupas são desenhadas em volumes sombreados na tentativa de transportar do quadro negro para a vida real, personagens de giz. (...) Cordas e tecidos manipulam conceitos de feio e bonito, eterno e efêmero, improvável e irônico (RONALDO FRAGA FLICKR, 2009).

Com um casting diversificado, Fraga repensa a velhice e infância enquanto fases da vida humana: "na passarela, o peso dos anos de um ancião às vezes se via no andar de uma das crianças e a vitalidade infantil, no caminhar de uma das modelos de 80" (FRAGA, 2017).

Como um risco de giz, que tem início e fim do traço, o começo da vida foi representado pelas crianças, enquanto o final, pelos velhos, representações que se entrelaçam e se opõe. Segundo Pereira (2012), um clima teatral e, por vezes, mórbido, forçava a reflexão, potencializado pelo trafegar de modelos-idosos juntamente com as crianças. "Uma fina ironia, um delicado jogo com a temporalidade, marcava a passagem do tempo, através de caminhadas na passarela/palco" (PEREIRA, 2012, p.155).

Além dessa questão temporal sobre a passagem da vida e a finitude, Fraga escolheu grupos que considerou como vulneráveis para representarem as temáticas do desamparo e do abandono, como exposto no trecho: "Numa cartela em preto, branco e cinza, falávamos da velhice como a sensação de uma casa vazia, fechada, com os móveis cobertos por lençóis brancos" (FRAGA, 2017).

A partir do século $X X$, com o aumento significativo da população idosa, sobretudo em países ricos como a França e os Estados Unidos, a velhice foi retratada como sinônimo de incapacidade/invalidez, surgindo como um "problema social". 
O aspecto econômico impulsionou sobremaneira essa representação à medida que o aumento do número de velhos passou a ser interpretado como uma ameaça à estabilidade financeira das empresas e do Estado, o que impacta todo o sistema capitalista (BEAUVOIR, 1976, PEIXOTO, 2006).

Sob a ótica capitalista, o material humano só desperta interesse à medida que pode ser produtivo, sendo rejeitado quando não se faz. Nessa perspectiva, a representação social da velhice é caracterizada pela inserção do indivíduo no processo de produção, definindo como velhos aqueles incapazes de produzir e, por isso, miseráveis (BEAUVOIR, 1976, PEIXOTO, 2006).

Segundo Beauvoir (1976), nessa visão produtivista, a velhice surge como uma degradação temida, como um segredo vergonhoso, como um peso social, do qual o jovem/adulto deseja desvencilhar sua imagem. O velho não sou eu, o velho é o outro, pois, em uma sociedade que exalta a juventude, ser velho é ser indesejável, portanto, abandonado e rejeitado. Como "casa vazia", a velhice também aparece na fala do estilista como sinônimo de ostracismo e morte social. A morte social, para Cordeiro (2009), tem relação com isolamento e solidão decorrente do afastamento compulsório de atividades na família e na coletividade, comuns para uma parcela da população velha.

Dessa forma, a inclusão de velhos em lugares dominados pela juventude leva aos espectadores do desfile a repensarem os estereótipos negativos ligados à velhice, que invisibilizam os idosos e os impedem de alcançarem a efetiva participação social. Além das questões temporais e de vulnerabilidade, o desfile também provoca a reflexão sobre a mutabilidade das definições de belo/feio: 
Eu quero chamar atenção pra coisas que eu acho lindo, eu acho lindo um bracinho enrugado, sabe? Eu acho lindo essa coisa da forma da boca que vai mudando, eu acho lindo o cabelo branco. E, principalmente, é uma beleza onde cada uma vai ser ela mesma. Eu não tô pegando mulheres e transformando essas mulheres para dar uma unidade na passarela: a que usa cabelo escovado vai estar de cabelo escovado, a que usa cabelo de coque vai estar com o cabelo em coque (FRAGA, 2009).

Assim, os conceitos de feio e bonito, eterno ou efêmero, ficavam evidentes quando os primeiros modelos-idosos lançavam o questionamento do irônico ou do improvável naquela passarela convertida em palco (PEREIRA, 2012).

Ao ver beleza nos signos do envelhecimento corporal, Fraga amplia as concepções do belo, rompendo com o ideal ligado aos seus padrões normativos de juventude e magreza. Suassuna (2008), em seu livro a Iniciação à Estética, afirma que a estética moderna procurava fazer do Belo apenas um dos tipos possíveis de algo mais amplo. Nessa perspectiva, o Belo estaria entre os vários tipos de Beleza existentes, e o velho e o gordo também seriam considerados sujeitos belos. No entanto, o body business, com auxílio da mídia, produziu um modelo único de beleza e impõs um padrão a ser seguido, no qual o consumo de produtos e serviços é o meio para atingir os chamados ideais de beleza. Nesse sentido, velhos e gordos passaram a ser sinônimos de feiura.

Fraga contrapõe-se a "moral da pele lisa": "No império da cultura audiovisual, hoje triunfante, a catástrofe se estampa nos traços visíveis do envelhecimento, que se consideram marcas de fraqueza ou sinais de uma derrota e, por tal motivo, seriam moralmente condenáveis" (SIBILIA, 2012, p.100). Assim, a "mora da pele lisa" impõe as tiranias do aspecto juvenil obrigatório e condena à invisibilidade tudo 
aquilo que se distancia dessa norma tão tenaz. Na era do culto ao corpo, novos tabus e pudores converteram a velhice num estado corporal vergonhoso (SIBILIA, 2012).

Nesse sentido, ao colocar velhos enrugados para desfilarem no principal evento de moda brasileiro e visibilizar os signos do envelhecimento corporal, como cabelos brancos, rugas e flacidez, Ronaldo Fraga marca seu posicionamento em relação à velhice, que afronta padrões únicos de beleza e desafia a "moral da pele lisa".

\section{COLEÇÃO AS PRAIAS DESERTAS CONTINUAM ESPERANDO POR NÓS DOIS, SPFW/2017}

Na $44^{\circ}$ Edição da São Paulo Fashion Week, de 2017, Ronaldo Fraga apresentou sua primeira coleção moda praia, cuja inspiração foi à década de 1920, período em que a elite brasileira descobriu o banho de mar. Com a proposta de "lançar luz sobre os invisíveis", o casting do desfile contou com deficientes, gordos e idosos, propondo uma reflexão a respeito do "corpo de praia", tido como corpo perfeito, sem rugas, sem marcas, sem gorduras e/ou flacidez. Dessa maneira, Fraga utilizou a imagem do velho para questionar as normas que incidem sobre o uso do corpo na atualidade (ALONSO; KODIK, 2017). Nas palavras do estilista:

Essa coleção fala de algo de que sempre falei: lançar luz sobre os invisíveis. O Brasil é um país em que os idosos, os deficientes, os gordos, os mestiços, todos são invisíveis. Invisíveis, porém humanos. Na moda praia, todas as pessoas têm o corpo perfeito. 0 homem tem a barriga sarada e a menina tem o bumbum redondo impecável, mas, na verdade, a perfeição não existe. Será que as pessoas ainda precisam cultuar essa imagem inatingível? (ALONSO; KODIK, 2017). 
Na década de 1920, a moda praia tinha inspiração francesa, envolvia toucas, roupões, vestidos e comprimento controlado pela força policial. A proposta de Fraga é uma releitura, um o retorno "àquela época com outras lentes, de mãos dadas com as novas tecnologias de tecidos $e$ construções de roupas". A coleção praia foi caracterizada por uma atmosfera de humor, sofisticação e transgressão, aliada à costura supersônica, tecnologia presente, pela primeira vez, nos uniformes do nadador Michael Phelps dos Jogos Olímpicos de 2008 (FASHION-FORWARD, 2019).

Ao falar sobre "corpo de praia", a proposta de Fraga vai ao encontro das afirmações do sociólogo e estudioso da corporeidade humana, David Le Breton (2010), que considera o corpo como um fato social e cultural, formado e educado pela cultura. Dessa forma, a perfeição exigida para o chamado "corpo de praia" reflete a cultura da "boa forma" presente nas sociedades ocidentais e, de sobremaneira, na sociedade brasileira contemporânea.

Goldenberg $(2007$, 2010) afirma que, mais do que em outras partes do mundo, a temática do corpo é central na vida e nos discursos dos brasileiros, sobretudo das mulheres. "No Brasil o corpo é um capital", um verdadeiro capital físico, simbólico, econômico e social (GOLDENBERG, 2010). Ser modelo é uma profissão almejada por grande parte das garotas do país e o principal "capital" de que dispõem essas profissionais "é o corpo magro, jovem, sarado e belo" (GOLDENBERG, 2007, p.27).

Devido a moral da "boa forma", a exposição do corpo, em nossos dias, não exige dos indivíduos apenas o controle de suas pulsões, mas também o (auto) controle de sua aparência física. O decoro, que antes parecia se limitar a não-exposição do corpo nu, se concentra, agora, na 
observância das regras de sua exposição (GOLDENBERG; RAMOS, 2002, p. 25).

$\mathrm{Na}$ contramão da cultura da "boa forma", a Figura 2 retrata um velho e uma velha apresentados de forma natural, com cabelos brancos, flacidez, rugas, sobrepeso e, ambos vestidos com roupas de praia.

A utilização de corpos velhos como modelos da moda praia quebra a expectativa do público consumidor à medida que o ideal de "corpo de praia" é o magro, sarado e jovem. Pode-se dizer que, "sob a moral da "boa forma", um corpo trabalhado, cuidado, sem marcas indesejáveis (rugas, estrias, celulites, manchas) e sem excessos (gorduras, flacidez) é o único que, mesmo sem roupas, está decentemente vestido" (GOLDENBERG; RAMOS, 2002, p. 29). Ao mesmo tempo, Fraga propõe um novo tipo de subversão, à medida que representa os idosos com corpos amplamente tatuados (algo não muito comum nos velhos mais tradicionais), sendo a tatuagem, uma forma de adorno e diferenciação corporal.

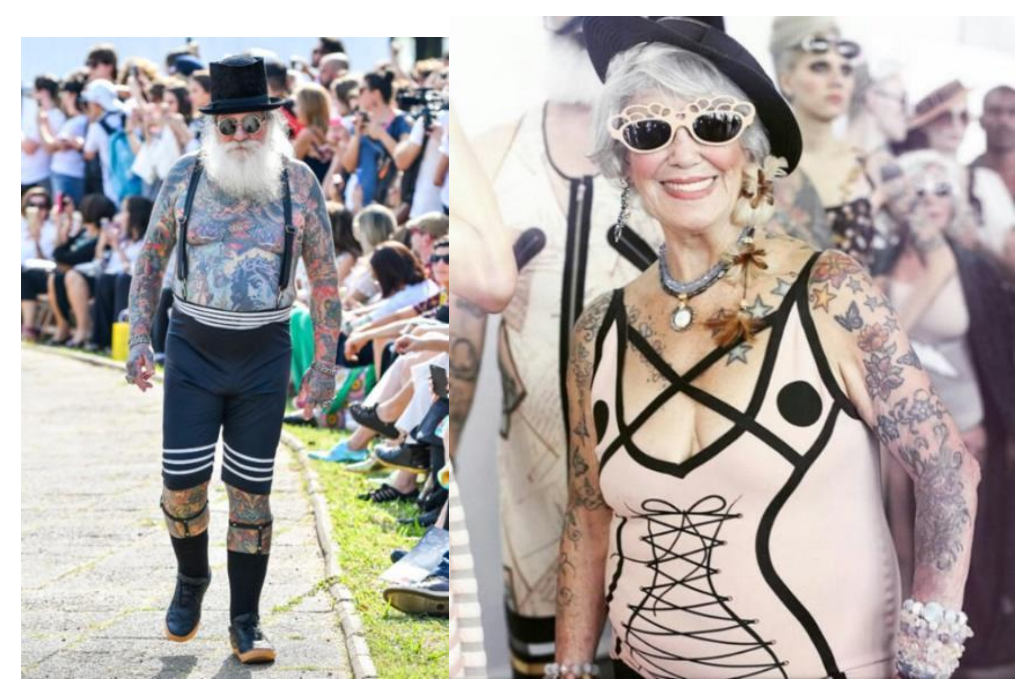

Figura 2: As praias desertas continuam esperando por nós dois Fonte: @ronaldofraga, $2017^{5}$ 
O maiô utilizado pela velha (Figura 2) sugere uma brincadeira com silhueta desenhada. A marcação de bicos de seios e da cintura e a amarração de espartilho criam um corpo diferente da conformação social do corpo velho, configurando um outro tipo de subversão apresentada pelo estilista.

Segundo Debert (2003), existe um conjunto de significados acionados pelos velhos na publicidade brasileira. Dentro dele, há um que remete à valorização de práticas inovadoras e subversivas de valores tradicionais, especialmente no que diz respeito à vida familiar, à sexualidade e ao uso de novas tecnologias.

Embora o estilista tenha se apropriado do conceito de subversão como estratégia de marketing, a utilização de modelos fora do padrão com peças menos reveladoras condiz com a expectativa do público e evita a rejeição da coleção, posto que as peças não evidenciam a flacidez, a gordura e outros elementos estigmatizadores censurados pela "moral da pele lisa" e pela "moral da boa forma".

\section{COLEÇÃO A COLINA DA PRIMAVERA, 2018/SPFW}

Durante a edição número 46 do SPFW, de Outubro de 2018, Ronaldo Fraga desfilou a coleção $A$ Colina da Primavera, que tematizou o conflito entre Israel e o Estado da Palestina. Segundo a release da coleção, a inspiração para o seu desenvolvimento se deu durante uma viagem do estilista à Tel-Aviv, cidade na costa israelense do mar Mediterrâneo, em uma cafeteria que anunciava $50 \%$ de desconto aos clientes árabes e judeus que aceitassem compartilhar a refeição em uma mesma mesa. Ademais, a intolerância religiosa, fonte do conflito na região, não foi 
percebida em relação a outras minorias (MESQUITA, 2018; ALONSO; AMARAL, 2018).

Para Fraga, judeus e palestinos selam a paz quando se juntam em uma mesa, enquanto, no Brasil, a polarização política e a intolerância que vitima negros, travestis e gays (e idosos) configuram uma verdadeira guerra (MESQUITA, 2018). Nesse sentido, por meio de uma analogia, $A$ Colina da Primavera teve como proposta a reflexão sobre a diversidade e intolerância (sexual, racial, etária, de classe, etc.) no Brasil.

No desfile, a passarela dividia-se ao meio pela presença de uma mesa. Ao redor dela, em paralelo, modelos desfilavam e, ao se encontrarem, davam-se as mãos e se beijavam. O primeiro casal apresentado foi composto por dois homens amputados, um deles com um lenço palestino e o outro com uma blusa jeans bordada com a estrela de Davi, símbolo do judaísmo. Além deles, o beijo se repetiu com um casal de velhos e duas mulheres jovens. Ao final de suas apresentações, os modelos sentavam-se a mesa e se serviam das comidas judaicas, árabes e sírias. No último ato, os modelos de pé, uniam às mãos, formando uma ciranda em torno da mesa.

Sobre as roupas, a coleção foi marcada pela presença do jeans como um material democrático, além do turquesa e das listras azuis, código reivindicado pelas duas religiões. Acessórios de inspiração étnica (óculos, cartolas, lenços, bolsas), efeitos de tapeçaria e motivos bordados faziam referência às culturas homenageadas. Outro destaque foi para as inscrições, em corrosão, com nomes de cristãos novos: Oliveira, Pereira, Moreira, Carvalho, Pinheiro, Figueira, Lima (ALONSO; AMARAL, 2018; MESQUITA, 2018; SCHNABL, 2018). 
Além do casal, modelos velhos se fizeram presentes em outros momentos do desfile, como mostra a Figura 3.

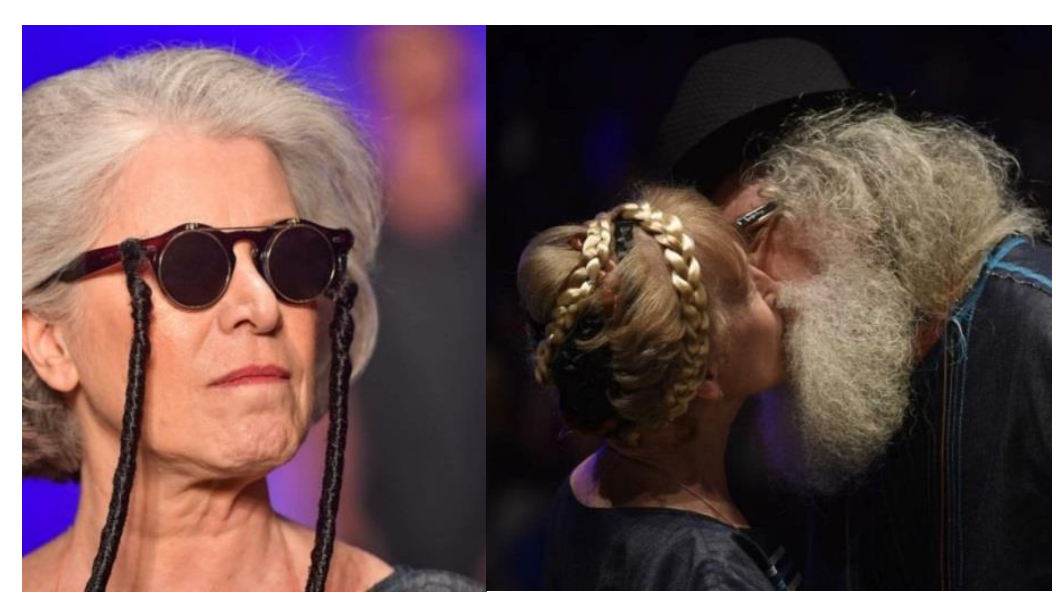

Figura 3: A Colina da Primavera Fonte: @ronaldofraga, 20176

A postura adotada pelo estilista com relação estética da velhice permaneceu semelhante às demais coleções: cabelos e barbas brancas, modelos acima do peso, rugas e flacidez.

$\mathrm{Na}$ Figura 3, o beijo do casal de velhos suscita a discussão em torno dos limites da velhice e da sexualidade na contemporaneidade. Em A Velhice, Simone de Beauvoir (1976, p.8) afirma que:

Os velhos provocam escândalo quando manifestam os mesmos desejos, sentimentos e reivindicações dos jovens: o amor e o ciúme, neles, parecem ridículos ou odiosos, a sexualidade é repugnante, a violência derrisória. Tem obrigações de dar exemplo de todas as virtudes.

Assim, o beijo proposto pelo estilista confronta a moral que impõe aos velhos um local de recolhimento e afastamento social, o que inclui as relações amorosas e o desejo sexual. Essa visão vem sendo questionada pelos estudiosos do envelhecimento.

Segundo Debert e Brigeiro (2012), durante as últimas três décadas, o discurso gerontológico vem atuando no 
sentido de desconstruir o mito que apregoa o fim da sexualidade juntamente com a chegada da velhice, ou seja, o "o mito da velhice assexuada". O intuito é o de demonstrar que, apesar haver uma redução do interesse e da atividade sexual, a libido pode permanecer por toda a vida, refutando, assim, a ideia de uma "assexualidade" na velhice, no sentido de falta de interesse ou de prática sexual.

Para esses autores, surgem novos discursos que se fundam na valorização e na centralidade da atividade sexual na velhice como parte das prescrições gerais para se alcançar envelhecimentos "saudáveis", "positivos" e "bemsucedidos". Dessa maneira, esses discursos instaurariam um "processo de erotização da velhice". Portanto, partiríamos de um enfoque mais antigo e culturalmente disseminado ilustrado pela frase "os velhos não têm vida sexual" para um discurso mais contemporâneo: "os velhos precisam ou devem fazer sexo para que alcancem uma vida plena e positiva" (DEBERT; BRIGEIRO, 2012).

Os ideais de subversão e atividade, incorporados pelos desfiles de Fraga, estão em consonância com o discurso gerontológico contemporâneo e caminham ao encontro da noção de velhice que configura a constituição dos movimentos de terceira idade.

Na França, a partir dos anos 1960, com a nova política social para a velhice, houve uma mudança na estrutura social e a elevação das pensões fez aumentar o prestígio dos aposentados. A expressão "terceira idade" no contexto francês a partir de 1962, em virtude da introdução de uma política de integração social da velhice visando à transformação da imagem dos jovens aposentados, que desejavam seu deslocamento com a imagem de "problema social" (PEIXOTO, 2006). O uso corrente do termo entre os estudiosos da velhice não é explicado pela referência à idade 
cronológica precisa, mas por ser esta uma forma de tratamento das pessoas de mais idade, que não adquiriu ainda uma conotação depreciativa (DEBERT, 2004, p.138).

A criação do termo "terceira idade" não é uma simples substituição terminológica, mas uma difusão ideológica que liga a velhice a uma nova etapa da vida capaz de oferecer novas oportunidades e experiências, marcadas pelo envelhecimento ativo e independente. Nessa perspectiva, surgiram instituições e agentes especializados no tratamento da velhice, como também foi criada uma gama de produtos e serviços destinados a esse público, além de profissionais especializados no fornecimento de orientações a quem não deseja tornar-se velho (PEIXOTO, 2006).

Como a moda é "é o reflexo de uma época, da cultura de um povo, uma denunciadora de períodos e locais, verdadeiramente, uma sinalizadora dos tempos" (BRAGA, 2005, p. 22) e, por ela, podemos compreender os fenômenos e as representações sociais, torna-se legítimo afirmar que essas mudanças na imagem que se tem dos velhos também tenham sido incorporadas pela moda e foram refletidas nos desfiles analisados, que apresentaram um velho ativo, subversivo, que se interessa pela moda, tatua o corpo, vai à praia e namora.

No geral, historicamente falando, o velho na moda tem sido sinônimo de desatualizado. Entretanto, percebe-se, desde o final do século $X X$, um movimento da publicidade de moda no sentido de se confirmar uma determinada variedade de ideais de beleza (gordos, deficientes, albinos, velhos etc.). Considerando a obsessão juvenil na sociedade contemporânea, o paradoxo de celebrar os idosos fisicamente parece prematuro para ser classificado como combate ao envelhecimento (MACKINNEY-VALENTIN, 2014). 
Existem idosos que participam de publicidade de moda e se sentem valorizados e incluídos. No entanto, MackinneyValentin (2014) destaca os casos de modelos mais velhos que integraram desfiles de grandes nomes da moda e se sentiram usados por uma estratégia comercial que articula questões de identidade e significação para fins de vantagens competitivas. Nesse sentido, trata-se mais de um mecanismo para alcançar ganho comercial, do que promover a tolerância social ou cultural.

Há, ainda, marcas que se utilizam da tendência da diversidade em seus materiais divulgativos, sem efetivamente criar mecanismos de inclusão em suas coleções. Para Aires (2019a; 2019b), esse tipo de inclusão performativa atinge outros públicos excluídos do mercado da moda, como no caso dos gordos, no qual algumas as marcas de moda se posicionam como inclusiva na publicidade, mas na prática, continuam mantendo a grade de numeração restrita a tamanhos menores e/ou adota posturas gordofóbicas em seu ambiente de varejo.

Pelo posicionamento político e pela preocupação em incluir em suas coleções roupas que atendam ao público mais velho (FRAGA, 2017), percebe-se que a marca Ronaldo Fraga busca a realização de uma inclusão efetiva, contribuindo para o rompimento de estereótipos negativos que associam à velhice à inatividade, ao ostracismo social, ao abandono das questões estéticas, da sexualidade, dentre outros.

Por naturalmente se propagar via imagens, a moda fazse elemento crucial para criar esta visibilidade que somente se dará de forma construtiva e inclusiva quando abraçar a diversidade, optando por exaltar o diverso, o multifacetado e o incomum em vez de padrões definidos de estilo, de corpos e de modelos de beleza (POLLINI, 2014, p.23). 


\section{CONSIDERAÇÕES FINAIS}

Pela análise da obra de Fraga, pode-se verificar a participação do público mais velho em diferentes momentos dos desfiles de sua marca homônima, seja como modelo ou na composição do cenário. A inclusão desse público na publicidade de moda tem sido recorrente em outras marcas do cenário nacional e internacional, o que comprova a incorporação dos movimentos de inclusão como uma das macrotendências contemporanêas.

Embora seja uma estratégia de marketing acertada frente às demandas sociais por representatividade e, mediante ao envelhecimento população e as previsões de crescimento exponencial das faixas etárias mais velhas, 0 estilista Ronaldo Fraga, manteve um posicionamento político e de enfrentamento das representações negativas da velhice. Em um movimento contrário, os desfiles analisados mostraram possíveis subversões dessas representações e apresentaram velhos ocupando espaços dominados pelo público jovem, como a passarela. Em outro momento o corpo velho foi tido como "corpo de praia", questionando o conceito de beleza ligado à estética jovem. O beijo do casal velho foi utilizado como uma proposta de tolerância e, ao mesmo tempo, de ruptura dos limites de sexualidade na velhice, representados pela máxima "velho não faz sexo!".

Assim, os velhos que, até então eram orientados a consumirem roupas de seus filhos e netos a fim de camuflarem a velhice e parecerem mais jovens, são convidados por Fraga a assumirem seus símbolos do envelhecimento e encontrarem beleza neles.

O posicionamento de Ronaldo Fraga pode inspirar outras marcas a ultrapassarem a inclusão performativa e a promoverem sua inclusão efetiva como público-alvo, pois, há 
estudos recentes que evidenciam a inclinação do idoso em consumir itens de moda e, ao mesmo tempo, as dificuldades que eles encontram na busca de roupas que consideram adequadas no atendimento de suas necessidades.

\section{NOTAS}

${ }^{1}$ Além dos desfiles citados, em 2015, em A fúria das sereias, 35 mulheres, entre 18 e 86 anos, vestidas de sereias e com os seios expostos, compunham a cenografia viva para a apresentação de uma coleção que falava da força do feminino em diferentes fases da vida (FRAGA, 2017).

${ }^{2}$ A partir da década de 1960 , os desfiles de moda deixaram de ser mera apresentação das coleções ao público consumidor final, passando a ser considerados como ferramentas de publicidade (SANT'ANNA; ROCHA JR.; GARCIA, 2009).

${ }^{3}$ Mundialmente conhecido pelos seus trabalhos e o caráter inovador de suas coleções, no ano de 2014, Fraga foi indicado para a Designs of the Year do Design Museum de Londres que contempla os trabalhos mais inovadores e originais apresentados no cenário mundial em um ano.

${ }^{4}$ FLICKR RONALDO FRAGA. Disponível em: https://www.flickr.com/photos/ronaldo_fraga/3275936241/in/phot ostream/. Acesso em: 20 mai. 2019.

5INSTAGRAM. Ronaldo Fraga. Disponível em: <https://www.instagram.com/fragaronaldo/?hl=pt-br>. Acesso em: 20 de outubro

de 2017.

${ }^{6}$ INSTAGRAM. Ronaldo Fraga. Disponível em: <https://www.instagram.com/fragaronaldo/?hl=pt-br>. Acesso em: 20 de outubro de 2017.

\section{REFERÊNCIAS}

ALONSO, Maria R.; AMARAL, Sérgio. Moda reage à realidade com poesia e inovação na São Paulo Fashion Week. O Estado de São Paulo. 23 out. 2018. Disponível em:

https://cultura.estadao.com.br/noticias/geral,moda-reage-arealidade-com-poesia-e-inovacao-na-sao-paulo-fashionweek,70002560789. Acesso em: 20 de jan. 2019.

AIRES, Aliana Barbosa. Diversidade e inclusão na moda: um mercado em transformação. Webinar Senac. Disponível em: https://www.eventials.com/SenacSP/webinar-senac-modainclusiva/?utm_campaign=webinar_diversidade_e_inclusao_na_mo 
da\&utm_content=confirmacao_de_inscricao\&utm_medium=rd_sta tion\&utm_source=email_GCR. Acesso em: 05 nov. 2019a.

AIRES, Aliana Barbosa. De gordas à plus size: a moda do tamanho grande. São Paulo: Estação das Letras. 2019b.

BEAUVOIR, de Simone. A velhice: a realidade incômoda. Rio de Janeiro: Nova Fronteira. 1976.

BRAGA, João. Reflexões sobre moda, volume I. In: BRAGA, João; NUNES, Mônica (Colab.). São Paulo: Editora Anhembi Morumbi, 2005a.

CORDEIRO, Domingos Sávio de Almeida. A morte em grupos de convivência de terceira idade. Congresso Brasileiro de Sociologia, 15, Rio de Janeiro, 2009. Anais (...). p. 220-220.

DEBERT, Guita Grin. A Reinvenção da Velhice: socialização e processos de reprivatização do envelhecimento. São Paulo: Edusp/Fapesb, 2004.

DEBERT, Guita Grin. O velho na propaganda. Cadernos Pagu, n.21. p.133-155. 2003. Disponível em: http://www.scielo.br/pdf/cpa/n21/n21a07.pdf. Acesso em: 20 mar. 2020.

DEBERT, Guita Grin; BRIGADEIRO, Mauro. Fronteiras de gênero e a sexualidade na velhice. Revista Brasileira de Ciências Sociais. v. 27 n. 80 outubro/2012. Disponível em: https://doi.org/10.1590/S0102-69092012000300003. Acesso em: 20 mar. 2020.

EUN-KYOUNG, Seo; EUN-YOUNG, Jang. Middle-Aged of the British Women's Apparel Purchase Situation Analysis. Journal of Fashion Business, v.13, n. 3, pp. 99-108. 2009. Disponível em: http://www.koreascience.or.kr/article/JAKO200933063805981.do. Acesso em: 20 mar. 2020.

FRAGA, Ronaldo. Entrevista concedida ao canal BOL VÍDEOS. SPFW Inverno 2009 - Entrevista com Ronaldo Fraga. BOL VÍDEOS, 2009. Disponível em: https://videos.bol.uol.com.br/video/spfw-inverno-2009-entrevista-com-ronaldo-fraga-04023066DCB95326. Acesso em: 20 mar. 2020.

FRAGA, Ronaldo. Instagram @fragaronaldo. Disponível em: <https://www.instagram.com/fragaronaldo/?hl=pt-br>. Acesso em 20 de out. 2017.

FRAGA, Ronaldo. Desfile Tudo é Risco de Giz- Ronaldo Fraga SPFW Inverno 2009. FLICKR. Disponível em: https://www.flickr.com/photos/ronaldo_fraga/3275936241/in/phot ostream/. Acesso em: 20 mai. 2019. 
FRAGA, Ronando. A Moda e o Novo Velho. Trip, 30 de mar. 2017. Disponível em: https://revistatrip.uol.com.br/trip/ronaldo-fragamoda-envelhecimento-consumo-depois-dos-60.

FASHION-FORWARD - FFW. Desfiles N44/SPFW, Ronaldo Fraga, FASHION-FORWARD/UOL, 30 out. 2018. Disponível em: https://ffw.uol.com.br/desfiles/sao-paulo/n44/ronaldofraga/1662952/. Acesso em: 20 mai. 2019.

G1 NOTÍCIAS. Modelos com mais de 60 anos ganham dinheiro em comerciais. G1 GLOBO. Rio de Janeiro. 10 de ago. 2011. Disponível em: http://g1.globo.com/bom-diabrasil/noticia/2011/08/modelos-com-mais-de-60-anos-ganhamdinheiro-em-comerciais.html. Acesso em: 20 out. 2017.

GOLDENBERG, Miriam. O corpo como capital. São Paulo: Estação das Letras e Cores, 2007.

GOLDENBERG, Miriam. O corpo como capital: gênero, casamento e envelhecimento na cultura brasileira. Redige, v. 1, n. 1, p. 192200, 2010.

GOLDENBERG, Miriam; RAMOS, Marcelo. S. A civilização das formas: o corpo como valor. In: GOLDENBERG, Miriam (Org.). Nu \& Vestido: Dez antropólogos revelam a cultura do corpo carioca. Rio de Janeiro: Record, 2002. p. 19-40.

KOZAR, Joy M.; LYNN DAMHORST, Mary. Older women's responses to current fashion models. Journal of Fashion Marketing and Management, $v$ 12, n. 3, pp. 338-350, 2008. Disponível em: i.org/10.1108/13612020810889290. Acesso em: 20 out. 2017.

LE BRETON, David. Antropologia do corpo e modernidade. 2. ed. Petrópolis, RJ: Vozes, 2012.

LOPEZ Y ROYO, Alessandra Bruni. Over 50 and doing what? Reflections on being a mature. In: International Women, Ageing and Media Research Summer School, 2324 July 2013. Disponível em: https://www.academia.edu/33205586/Over_50_and_doing_what_ Reflections_on_being_a_mature_model. Acesso em: 20 out. 2017.

MACKINNEY-VALENTIN, Maria. Face value: subversive beauty ideals in contemporary fashion marketing. Fashion, Style \& Popular Culture, v. 1, n.1, pp. 13-27, 2014. Disponível em: http://dx.doi.org/10.1386/fspc.1.1.13_1. Acesso em: 20 out. 2017.

MENDONÇA, Maria Luiza Martins; FERREIRA, Ceiça. Envelhecimento feminino, consumo e protagonismo. É a (voz da) vovozinha! Comunicação, mídia e consumo, v.11 n.32, p.119136, set/dez. $2014 . \quad$ Disponível em: http://revistacmc.espm.br/index.php/revistacmc/article/view/838. Acesso em: 20 out. 2017. 
MESQUITA, Giuliana. Ronaldo Fraga aborda a intolerância com beijaço e banquete na SPFW. Folha de São Paulo, 23 out. 2018. Disponível em: https://www1.folha.uol.com.br/ilustrada/2018/10/ronaldo-fragaaborda-a-intolerancia-com-beijaco-e-banquete-naspfw.shtml?origin=folha. Acesso em: 20 de jan. 2019.

PEIXOTO, Clarice. Entre o estigma e a compaixão e os termos classificatórios: velho, velhote, idosos, terceira idade. BARROS, M. M. L. (Org.). Velhice ou terceira idade? Rio de Janeiro: FGV. 2006.

POLLINI, Denise. O envelhecimento e a moda: tecendo reflexões. Mais 60 Estudos sobre o Envelhecimento, v. 25, n. 61, p. 825, Nov. 2014.2 Disponível em: https://www.sescsp.org.br/files/edicao_revista/4744d5f9-3c1244ec-82e3-c9a847474c80.pdf. Acesso em: 20 de jan. 2019.

REVISTA CLAUDIA. O novo velho; o idoso se reinventou e leva a vida sem monotonia. Revista Claudia, n. 3. a. 43, mar. 2004, p. 131.

SANT'ANNA, Armando; ROCHA JR., Ismael; GARCIA, Luiz F. D. Propaganda: teoria, técnica e prática. 8. ed. rev. e ampl. São Paulo: Cengage Learning, 2009.

SCHNABL, Alexandre. SPFW: Ronaldo Fraga e a mensagem de tolerância. O Fluminense, 24 out. 2018. Disponível em: https://www.ofluminense.com.br/pt-br/revista/spfw-ronaldofraga-e-mensagem-de-toler\%C3\%A2ncia. Acesso em: 20 de jan. 2019.

SIBILIA, Paula. O corpo velho como uma imagem com falhas: a moral da pele lisa e a censura midiática da velhice. Comunicação, mídia e consumo, São Paulo, a.9, v.9, n.26, p.83-114, nov. $2012 . \quad$ Disponível em: http://revistacmc.espm.br/index.php/revistacmc/article/view/345. Acesso em:20 de jan. 2019.

SUASSUNA, Ariano. Iniciação à Estética. 9 ed. Rio de Janeiro: José Olympio. 2008. 